\title{
Effect of Different Nucleating Agents on the Crystallization of Ziegler-Natta Isotactic Polypropylene
}

\author{
Felipe Avalos-Belmontes, ${ }^{1}$ Luis Francisco Ramos-deValle, ${ }^{2}$ \\ Adriana Berenice Espinoza-Martínez, ${ }^{2}$ Juan Guillermo Martínez-Colunga, ${ }^{2}$ \\ Eduardo Ramírez-Vargas, ${ }^{2}$ Saul Sánchez-Valdés, ${ }^{2}$ Jose Carlos Ortíz-Cisneros, ${ }^{1}$ \\ Esperanza Elizabeth Martínez-Segovia, ${ }^{2}$ and Flora Itzel Beltrán-Ramírez ${ }^{2}$ \\ ${ }^{1}$ Facultad de Ciencias Químicas, Universidad Autónoma de Coahuila (UAdeC), Boulevard V. Carranza and González-Lobo, \\ 25000 Saltillo, COAH, Mexico \\ ${ }^{2}$ Centro de Investigación en Química Aplicada (CIQA), Boulevard Enrique Reyna No. 140, 25294 Saltillo, COAH, Mexico
}

Correspondence should be addressed to Felipe Avalos-Belmontes; favalos@uadec.edu.mx and Luis Francisco Ramos-deValle; luis.ramos@ciqa.edu.mx

Received 26 January 2016; Revised 6 May 2016; Accepted 17 May 2016

Academic Editor: Marta Fernández-García

Copyright (c) 2016 Felipe Avalos-Belmontes et al. This is an open access article distributed under the Creative Commons Attribution License, which permits unrestricted use, distribution, and reproduction in any medium, provided the original work is properly cited.

\begin{abstract}
Ziegler-Natta isotactic polypropylene (iPP) was melt mixed with four different nucleating agents (carbon nanotubes (CNT), carbon nanofibers (CNF), lithium benzoate (LiBe), and a sorbitol derivative (Millad)) in order to study their effect on the crystallization of iPP. It was found that the four different nucleating agents promote the alpha crystalline form. At $0.01 \mathrm{wt} \%$, the carbon nanoparticles produced the higher crystallization temperature " $T_{c}$ " $\left(\sim 119^{\circ} \mathrm{C}\right)$, whereas, at $0.10 \mathrm{wt} \%$, LiBe and Millad produced a markedly higher $T_{c}\left(\sim 125^{\circ} \mathrm{C}\right) . T_{c}$ of pure iPP was $111^{\circ} \mathrm{C}$. With $0.1 \mathrm{wt} \%$ nucleating agent, at $120^{\circ} \mathrm{C}$, the crystallization half-life time of PP, when using LiBe or Millad, was 15 times faster than for pure PP, whereas, when using carbon nanoparticles, it was $20-25$ times faster. At $135^{\circ} \mathrm{C}$, with $0.01 \mathrm{wt} \%$ nucleating agent, the isothermal crystallization process of iPP was completed after $25 \mathrm{~min}$, as well as with Millad. With LiBe, it was completed after just $15 \mathrm{~min}$ and, with any of the carbon nanoparticles, it was practically over after only a couple of minutes.
\end{abstract}

\section{Introduction}

Isotactic polypropylene is an important polyolefin used in the global market due to the combination of very good properties and low cost. However, because of polypropylene being a semicrystalline polymer, many of its properties depend on its crystalline characteristics, which can be modified by means of different methods and techniques. The addition of nucleating agents, for example, will induce a more uniform crystal size and crystal structure. This in turn, will induce a higher crystallization temperature, which eventually will result in shorter molding cycles. Improvements in the mechanical and thermal properties include increased modulus without sacrificing impact strength, increased thermal stability $[1$, $2]$, and increased clarity for special visual effects when concerning the optical properties [3].
Polypropylene with its relatively slow crystallization rate and crystal size from 50 to $150 \mu \mathrm{m}$, and depending on the particular characteristics of the polymer and thermal treatment, has a typical white appearance. But, by decreasing the crystal size below the wavelength of visible light, polypropylene becomes quite transparent $[1,4,5]$. When the nucleating agent reduces the crystal size of the polypropylene to such an extent, the agent is also known as a clarifier. Clarified polypropylene presents higher clarity and improved polymer strength. This makes the polymer a promising substitute of polystyrene in some applications. Currently, clarified polypropylene finds application in housewares, containers, blow molded bottles, medical syringes and vials, thermoformed containers, and extruded and blown films [6].

In addition to the above-mentioned effects, the content of alpha, beta, and gamma crystalline forms can also be 
TABLE 1: Comparison of size and surface area of the four different nucleating agents.

\begin{tabular}{|c|c|c|c|c|}
\hline & CNT & $\mathrm{CNF}$ & $\mathrm{LiBe}$ & Millad \\
\hline$L(\mu \mathrm{m})$ & 10 & 20 & - & - \\
\hline$D(\mu \mathrm{m})$ & 0.050 & 0.120 & 10.0 & 15.0 \\
\hline$\rho\left(\mu \mathrm{g} / \mu \mathrm{m}^{3}\right)$ & $2.1 \times 10^{6}$ & $2.1 \times 10^{6}$ & $1.1 \times 10^{6}$ & $1.1 \times 10^{6}$ \\
\hline \multicolumn{5}{|l|}{ Approximately } \\
\hline Vol of 1 particle $\left(\mu \mathrm{m}^{3}\right)$ & 0.02 & 0.23 & 524 & 1,767 \\
\hline Wt of 1 particle $(\mu \mathrm{g})$ & $4.12^{-8}$ & $47.50^{-8}$ & $5.76^{-4}$ & $19.40^{-4}$ \\
\hline Number of particles in $100 \mathrm{mg}$ & $2.43^{+12}$ & $21.10^{+12}$ & $1.74^{+8}$ & $0.51^{+8}$ \\
\hline Surface area of 1 particle $\left(\mu \mathrm{m}^{2}\right)$ & 1.60 & 7.5 & 314 & 707 \\
\hline Surface area in $100 \mathrm{mg}\left(\mu \mathrm{m}^{2}\right)$ & $3.81^{+12}$ & $1.59^{+12}$ & $5.45^{+10}$ & $3.64^{+10}$ \\
\hline Ratio of surface areas* & 100 & 40 & 1.5 & 1 \\
\hline
\end{tabular}

${ }^{*}$ Ratio of surface areas of the different nucleating agents, to Millad, when having $100 \mathrm{mg}$ of each, taking the surface area of $100 \mathrm{mg}$ of Millad as 1 . For example, $100 \mathrm{mg}$ of CNT will have 100 times the surface area of $100 \mathrm{mg}$ of Millad.

CNT and CNF were considered as cylinders and LiBe and Millad as spheres for the calculation of volume, weight, and surface area.

—: at any wt\%, there will always be between 30 and 100 times more surface area in carbon nanoparticles than in LiBe or Millad.

altered by selecting the appropriate nucleating agent $[7,8]$. In the last 10 years, carbon nanostructures such as carbon nanotubes (CNT) and carbon nanofibers (CNF) have been used as effective nucleating agents for polypropylene $[9,10]$. Some authors have reported that the addition of nanotubes from 0.1 to $5 \mathrm{wt} \%$ increased the crystallization temperature of PP composites with respect to the pure PP and enhanced the mechanical, electrical, and thermal properties [11, 12].

This paper examines the nucleating ability of very small amounts of CNT, CNF, dimethylbenzylidene sorbitol (Millad), and lithium benzoate (LiBe) for the crystallization of an isotactic Ziegler-Natta polypropylene.

\section{Experimental}

2.1. Materials. The isotactic polypropylene (iPP) used in this study was a Ziegler-Natta polypropylene from Indelpro, Mexico, with an average molecular weight (MW) of 300,000, molecular weight distribution (MWD) of 3.4, and melt flow index (MFI) (at $230^{\circ} \mathrm{C}$ with $2.16 \mathrm{~kg}$ ) of $11 \mathrm{~g} / 10 \mathrm{~min}$. This iPP presented a crystallization temperature $\left(T_{c}\right)$ and melting temperature $\left(T_{m}\right)$ of 111 and $160^{\circ} \mathrm{C}$, respectively.

Chemicals used as nucleating agents were multiwalled carbon nanotubes (CNT), from NanoLab, USA; carbon nanofibers (CNF), Pyrograf III, from Applied Sciences, USA; lithium benzoate (LiBe), with a melting point of $\sim 370^{\circ} \mathrm{C}$, from Micronisers Ltd., Australia; and 1,3:2,4-bis(3,4dimethylbenzylidene sorbitol), Millad 3988 (Millad), with a melting point of $\sim 250^{\circ} \mathrm{C}$, from Milliken, USA.

Considering CNT and CNF with a rod-like form and $\mathrm{LiBe}$ and Millad with a quasi-spherical form, Table 1 presents a comparison of their approximate size and geometric characteristics.

2.2. Preparation of Composites. iPP composites with $0.1 \mathrm{wt} \%$ of each nucleating agent were prepared in a $250 \mathrm{~cm}^{3}$ capacity mixing chamber with roller type rotors, coupled to a Brabender torque rheometer. The composites were prepared via melt mixing for a period of $12 \mathrm{~min}$, at $170^{\circ} \mathrm{C}$ and $50 \mathrm{rpm}$ rotor speed.

These composites with $0.1 \mathrm{wt} \%$ of nucleating agent were then used as master batches and diluted for the preparation of the $0.001,0.01,0.05$, and $0.08 \mathrm{wt} \%$ of nucleating agent.

\subsection{Characterization}

2.3.1. Differential Scanning Calorimetry (DSC). DSC measurements were performed on a Perkin Elmer DSC 7, Pyris, under a nitrogen flow. Weight of each sample was always $10 \pm 1 \mathrm{mg}$.

The effect of the different nucleating agents on the rate of crystallization and on the nucleating efficiency of the different nucleating agents was studied via dynamic conditions, whereas the effect of the different nucleating agents on the kinetic characteristics of the process of crystallization was studied via isothermal conditions.

2.3.2. Dynamic Crystallization. The crystallization temperature $\left(T_{c}\right)$ was calculated as follow: samples were first heated from room temperature to $200^{\circ} \mathrm{C}$ at $10^{\circ} \mathrm{C} / \mathrm{min}$ and held there for $3 \mathrm{~min}$ to erase any thermal history. The samples were then cooled down to $50^{\circ} \mathrm{C}$ at $-10^{\circ} \mathrm{C} / \mathrm{min}$. From this cooling process, the temperature at the maximum peak was taken as $T_{c}$.

2.3.3. Isothermal Crystallization. These were carried out at various isothermal temperatures ranging from 115 to $127^{\circ} \mathrm{C}$. All samples were first heated to $200^{\circ} \mathrm{C}$ at $10^{\circ} \mathrm{C} / \mathrm{min}$ and held there for $3 \mathrm{~min}$ to erase the previous thermal history. Subsequently, they were cooled at $-50^{\circ} \mathrm{C} / \mathrm{min}$ to the desired isothermal temperature and held at that temperature until complete crystallization.

2.3.4. Polarizing Optical Microscopy (POM). Crystalline morphology of iPP and its composites was investigated through a Mettler Toledo FP900, coupled to a Zeiss contrast phase microscope. Additionally, a Samsung video camera model SCC-131A was attached to the microscope. The amplification 


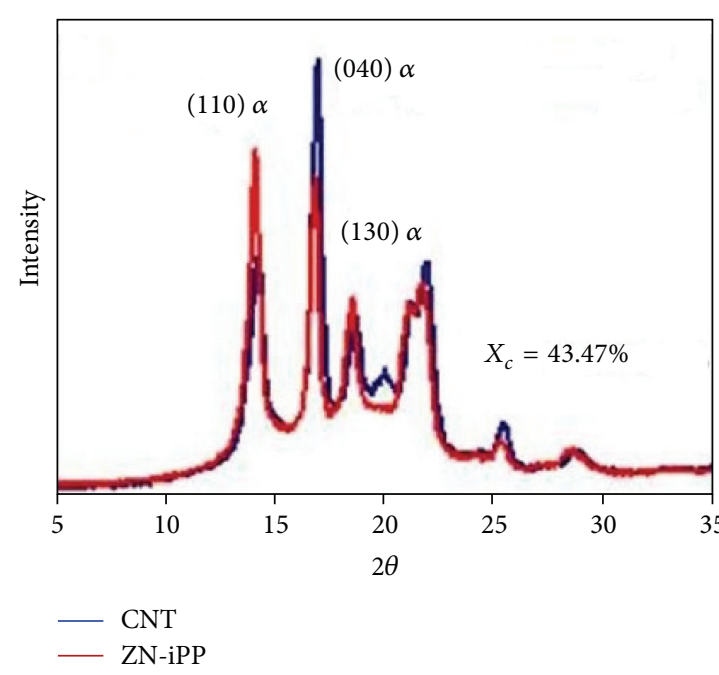

(a)

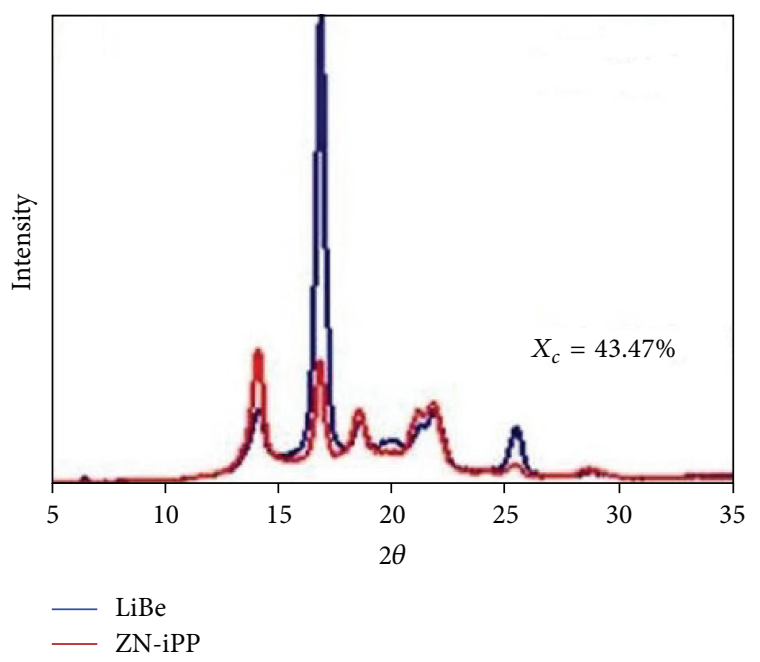

(c)

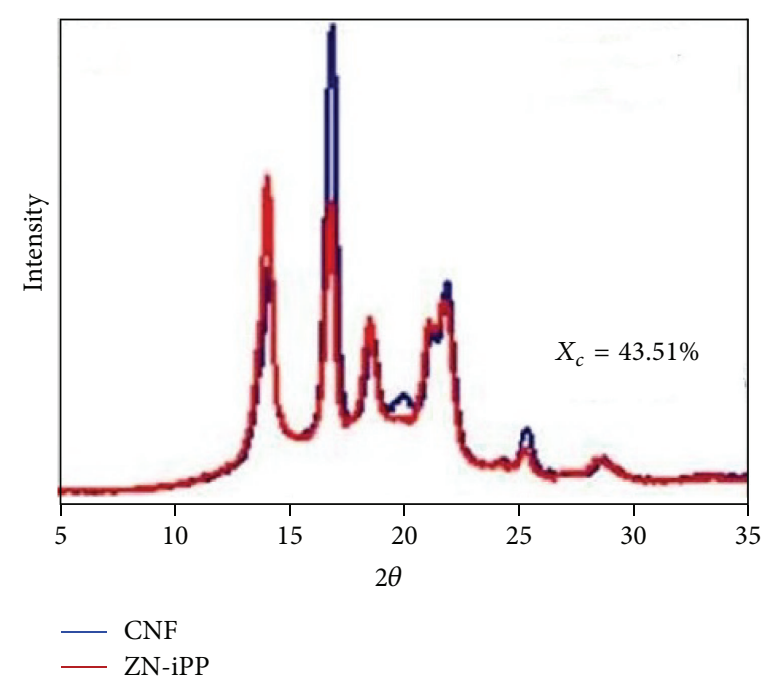

(b)

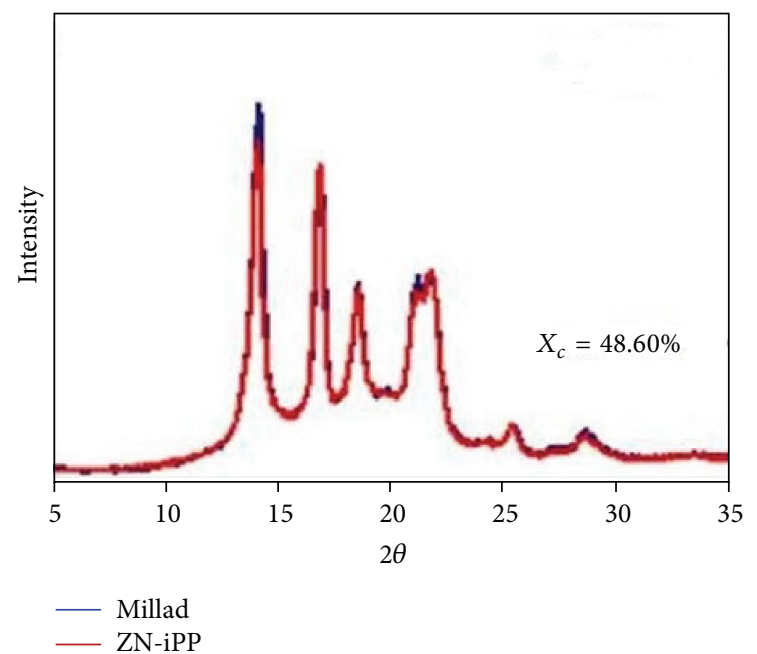

(d)

FIGURE 1: WAXD diffractograms of iPP composites at $0.1 \mathrm{wt} \%$ of nucleating agent.

used was 10x times 20x. The experiments were performed using isothermal crystallization. Samples were heated to $200^{\circ} \mathrm{C}$ at a heating rate of $10^{\circ} \mathrm{C} / \mathrm{min}$ and held there for 3 minutes to remove thermal history and then cooled down to $135^{\circ} \mathrm{C}$ at $-20^{\circ} \mathrm{C} / \mathrm{min}$. The samples were then held at $135^{\circ} \mathrm{C}$ for $30 \mathrm{~min}$. All experiments were run in air atmosphere. The time, at which each sample reached $T_{c}$, was designated as time zero $\left(t_{0}\right)$. In each case, a photograph was taken at time zero; thereafter, a new photograph was taken, either every $30 \mathrm{sec}, 15 \mathrm{sec}$, or more often, depending on how fast the crystallization occurred.

2.3.5. Wide Angle X-Ray Diffraction (WAXD). The crystalline structure of all samples was assessed using X-ray diffraction analysis. In this case, the composites with $0.1 \mathrm{wt} \%$ of additive were selected to determine the crystal type induced by the addition of the different nucleating agents. The XRD analyses were carried out in a Siemens D5000 diffractometer, from 5 to 35 in $2 \theta$. Disc shaped samples of $25 \mathrm{~mm}$ in diameter and $1 \mathrm{~mm}$ thick were analyzed.

\section{Results and Discussion}

3.1. Crystalline Structure of iPP Composites. To study the effect of the different nucleating agents on the polymorphism of iPP, all samples were examined by means of WAXD. It was reasoned that if there was any formation of beta crystals by the incorporation of the nucleating agents, this phenomenon will be more evident at the highest concentration. Thus, the X-ray analysis was carried out on the composites with $0.1 \mathrm{wt} \%$ of nucleating agent. Figure 1 shows the WAXD patterns of pure $\mathrm{iPP}$ and iPP with nucleating agents. It can be observed that the four composites display the same characteristic diffracting peaks corresponding to the planes (110), (040), and (130) of the $\alpha$-form, whereas the peak corresponding to the plane (300), characteristic of the $\beta$ form (at around the $16.0^{\circ}$ on the 


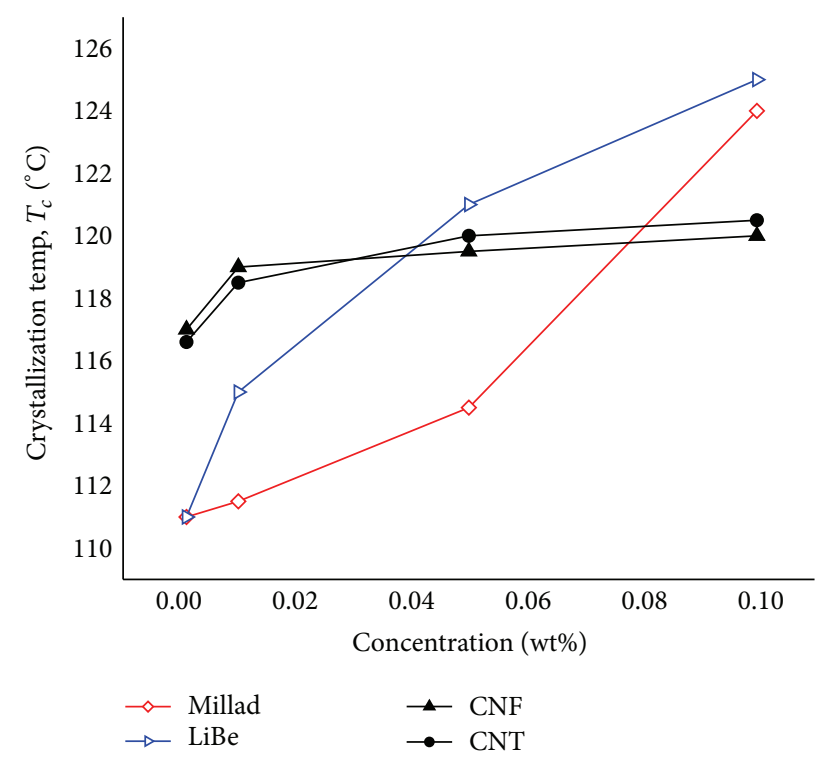

FIGURE 2: Variation of the crystallization temperature $\left(T_{c}\right)$ of iPP with the nucleating agents concentration $(0.001,0.01,0.05$, and $0.10 \mathrm{wt} \%)$.

$2 \theta$ range), is absent. This confirms that Millad, $\mathrm{LiBe}, \mathrm{CNF}$, and CNT are $\alpha$-nucleating agents for iPP.

In this respect, it has been reported that Millad and CNT are not able to induce the $\beta$ form [13-15], while there is no reported data for the $\mathrm{CNF}$ and LiBe. Furthermore, it can be observed in Figure 1 that there was an increase of the (040) plane at the expense of the (110) plane. The LiBe nucleating agent induces the greatest displacement to the alpha form, while Millad exerts an effect comparable to that of the carbon nanoparticles.

In this respect, the crystallinity degree $\left(X_{c}\right)$ of the composites was also determined from the X-ray diffractograms. This crystalline content was obtained from the total area under the diffractograms, after subtracting the area corresponding to the amorphous phase [16].

The $X_{c} \%$ values are included inside the WAXD plots of Figure 1 . Note that these crystalline degrees $\left(X_{c} \%\right)$ were obtained on samples with $0.1 \mathrm{wt} \%$ of nucleating agent. For the pure polymer, the crystalline content was found to be $42.0 \%$ and, in general terms, it can be said that the incorporation of the studied nucleating agents slightly increased the $X_{c} \%$ of the carbon nanoparticles composites (by $\sim 1.5$ percentage point, i.e., 42.0 to 43.5 ), whereas it markedly increased the $X_{c} \%$ of the LiBe and Millad composites (by $\sim 7.0$ percentage points, i.e., 42.0 to 49.0 ).

3.2. Nonisothermal Crystallization Behavior of iPP Composites. Table 2 presents the particular crystallization temperatures of the iPP composites with the different nucleating agents.

Additionally, Figure 2 presents the effect of the different nucleating agents on $T_{c}$, as a function of concentration, in nonisothermal experiments. CNT and CNF showed a strong nucleating effect at very low concentrations $(0.001$
TABLE 2: Crystallization temperature $\left({ }^{\circ} \mathrm{C}\right)$ of the iPP composites as a function of the nucleating agent concentration.

\begin{tabular}{lcccc}
\hline $\begin{array}{l}\text { Nucleating agent } \\
\text { concentration, wt\% }\end{array}$ & Millad & LiBe & CNF & CNT \\
\hline 0.001 & 111 & 111 & 117 & 116.6 \\
0.01 & 110 & 116 & 119 & 118.5 \\
0.05 & 111 & 123 & 119.5 & 120 \\
0.10 & 124 & 125 & 120 & 120.5 \\
\hline
\end{tabular}

and $0.01 \mathrm{wt} \%$ ), increasing the crystallization temperature up to $119-120^{\circ} \mathrm{C}$; but this effect leveled off; that is, the carbon nanoparticles reached their saturation point and $T_{c}$ remained at ca. $120^{\circ} \mathrm{C}$ even at the highest concentration $(0.10 \mathrm{wt} \%)$.

$\mathrm{LiBe}$, on the other hand, started to have an effect on the crystallization temperature at a slightly higher concentration and, thereafter, even surpassed the effect of the carbon nanoparticles, reaching a crystallization temperature above $124^{\circ} \mathrm{C}$ at $0.10 \mathrm{wt} \%$ [17]. Finally, Millad showed no effect at the low concentrations but showed an excellent effect on increasing $T_{c}$ at the highest concentration ( $\left.0.10 \mathrm{wt} \%\right)$ equaling the effect of LiBe.

Polypropylene is known to present polymorphism which depends on the catalysts and polymerization conditions used during its synthesis. Its chain structure can contain randomly distributed stereo and/or regio defects. In this sence, van der Meer et al. [18] found that the crystal growth rate decreases linearly with the fraction of defects, but it is more affected by the presence of regio defects than stereo defects.

While studying the crystallinity and mechanical properties of metallocene catalyzed polypropylene, De Rosa et al. [19] found that the presence of rr defects affects its polymorphism and mechanical properties, inducing the formation of gamma type crystals. The authors found that when the concentration of rr defects is low (3-4\%), the polymer presents a melting temperature above $130^{\circ} \mathrm{C}$ and mechanically the polymer behaves as a stiff thermoplastic material. But if the concentration of rr defects is greater (4$6 \%$ ), the melting temperature lies between 115 and $120^{\circ} \mathrm{C}$ and the polymer behaves as a flexible thermoplastic material.

On the other hand, Krache et al. [7] studied the effect of nucleating agents on the polymorphism of metallocene and Ziegler-Natta polypropylenes and found that the formation of beta type crystals depends on the type and concentration of nucleating agent, as well as on the cooling rate. As a result, the decreased tacticity of metallocene polypropylene in combination with the effect of nucleating agents renders a more complex morphology than that in the Ziegler-Natta polypropylene. In the metallocene samples, the stereo defects are randomly distributed and therefore are more likely to be incorporated within crystals.

This explains why $T_{c}$ of Ziegler-Natta iPP composites is higher than that of metallocene iPP composites reported elsewhere [5]. On the other hand, Beck [20] found that the type of structure of the nucleating agent determines its effectiveness. In this sense, it is known that some nucleating agents of PP act via epitaxial interactions such as benzoic 
TABLE 3: Nucleating efficiency [\%] of the four different nucleating agents on iPP composites as a function of concentration.

\begin{tabular}{lcccc}
\hline $\begin{array}{l}\text { Nucleating agent } \\
\text { concentration, wt } \%\end{array}$ & Millad & LiBe & CNF & CNT \\
\hline 0.001 & 1 & 1 & 24.6 & 20.9 \\
0.01 & 2 & 15 & 30.7 & 28.3 \\
0.05 & 10 & 40 & 32.6 & 33.8 \\
0.08 & 26 & 49 & 34.6 & 35.1 \\
0.10 & 45 & 52 & 35.7 & 36.3 \\
\hline
\end{tabular}

acid and its salts [21]. The more ordered structure of ZieglerNatta iPP, as compared to that of metallocene iPP, favors the crystallographic interactions with nucleating agents, as observed in the $T_{c}$ results presented herewith, particularly with those agents that have similar unit cell structure to that of PP, as LiBe [22]. The carbon nanoparticles, due to their very high surface area, reach the saturation point very rapidly; the great number of nuclei sites overcomes the difference in the crystallizable block segments of the polymer. This would explain why, at very low concentrations, the carbon nanoparticles perform better in Ziegler-Natta iPP than in metallocene iPP. In this case, due to the small number of nuclei particles, the effect of the crystallizable polymer segments length is dominant.

3.3. Nucleating Efficiency in terms of $T_{c}$. There are two ways of assessing the nucleating efficiency of additives for polypropylene, depending on the way the crystallization takes place. One is when the crystallization is carried out under dynamic conditions, where the measured parameter is the crystallization temperature and the simplest way is to establish an arbitrary scale [20] or use Fillon's method [23]. This method defines the ideal situation of self-nucleated polypropylene and takes the crystallization temperature of the self-nucleated PP $\left(T_{c_{c_{\max }}}\right)$ as the upper limit $(100 \%)$, which in this case was taken as $138^{\circ} \mathrm{C}[13,24,25]$. However, the crystallization temperature of the pure polymer $\left(T_{c_{1}}\right)$ is the lower limit $(0 \%)$, and in this case it was taken as $110^{\circ} \mathrm{C}$. Thus, the nucleating efficiency is given by

$$
\mathrm{NE}=100 * \frac{T_{c_{\mathrm{NA}}}-T_{c_{1}}}{T_{c_{\text {max }}}-T_{c_{1}}},
$$

where $T_{c_{N A}}$ is the measured crystallization temperature with a particular nucleating agent.

Self-nucleation studies for polypropylene $[13,24,25]$ give values for $T_{c_{\text {max }}}$ (the upper limit) between 137 and $140^{\circ} \mathrm{C}$ for a Ziegler-Natta iPP, that is, approximately 25 to 28 degrees above the crystallization temperature of the pure polymer. In the present study, $T_{c_{\text {max }}}$ of iPP was taken as $138^{\circ} \mathrm{C}$. This value is an average of 28 degrees above the crystallization temperature of the pure polymer $\left(T_{c_{1}}=110^{\circ} \mathrm{C}\right)$.

Following (1), the efficiency of the nucleating agents is presented in Table 3.

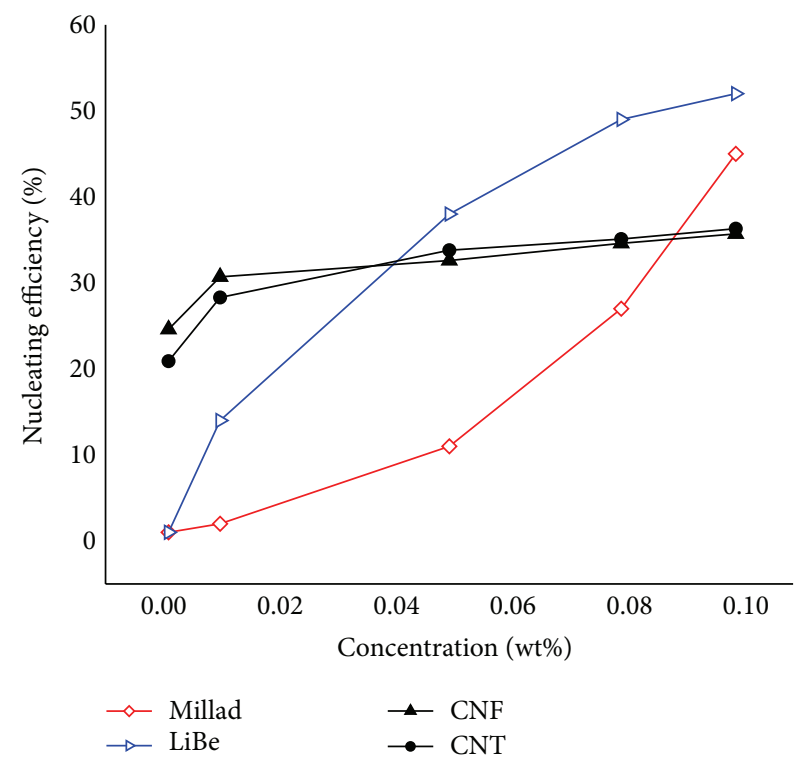

FIGURE 3: Variation of the nucleating efficiency of the different nucleating agents with their concentration $(0.001,0.01,0.05$, and $0.10 \mathrm{wt} \%)$.

The resulting nucleating efficiencies are not especially high. Higher results have been reported [25-27], but what has to be kept in mind is that the highest nucleating agent concentration used was $0.1 \mathrm{wt} \%$, which is lower than that reported in many similar studies, especially for Millad and LiBe $[28,29]$.

However, it is worth to emphasize the good nucleating efficiency of Millad and LiBe when used at a concentration of $0.1 \mathrm{wt} \%$ as shown in Table 3 and Figure 3.

What is clear from Figure 3 is that the carbon nanoparticles apparently tend to reach their saturation point at very low concentrations, $0.01-0.05 \mathrm{wt} \%$, where their NE reaches a maximum of ca. $30-35 \%$. Millad and LiBe, on the other hand, seem to be very poor nucleating agents at the low concentrations studied but easily surpass the NE of the carbon nanoparticles at concentrations above $0.10 \mathrm{wt} \%$. At $0.10 \mathrm{wt} \%$, Millad and LiBe do not even seem to be near their saturation point.

The above mentioned could be because, at any weight concentration, the number of carbon nanoparticles surpasses the number of Millad or LiBe particles by approximately 6 orders of magnitude (Table 1). That is, at the low concentrations used in this study, the number of Millad or LiBe nuclei is still very small compared to the number of CNT or CNF nuclei. And it is until the Millad or LiBe nuclei population increases when these start to show the strong nucleating effect. The small number of Millad or LiBe particles, at the lower concentrations, gives rise to the large spherulite sizes observed in Figure 5.

The crystallization kinetics of the PP compositions studied was carried out based on the Avrami model. This theory has been often used to analyze the crystallization of PP [1921]. This model does not account for the secondary crystallization, but it has been found that secondary crystallization is not relevant in PP [8]. 


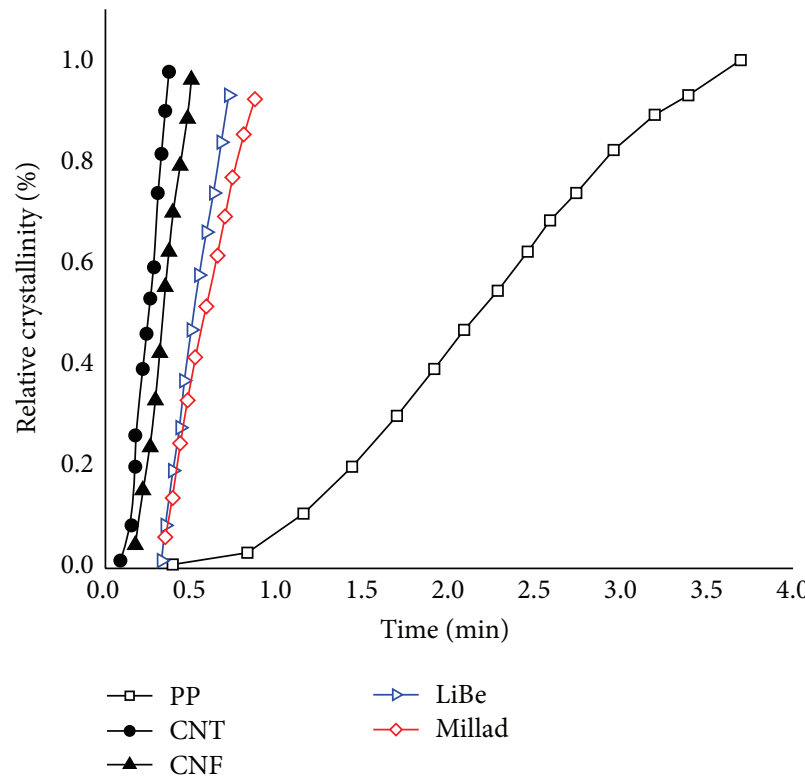

(a)

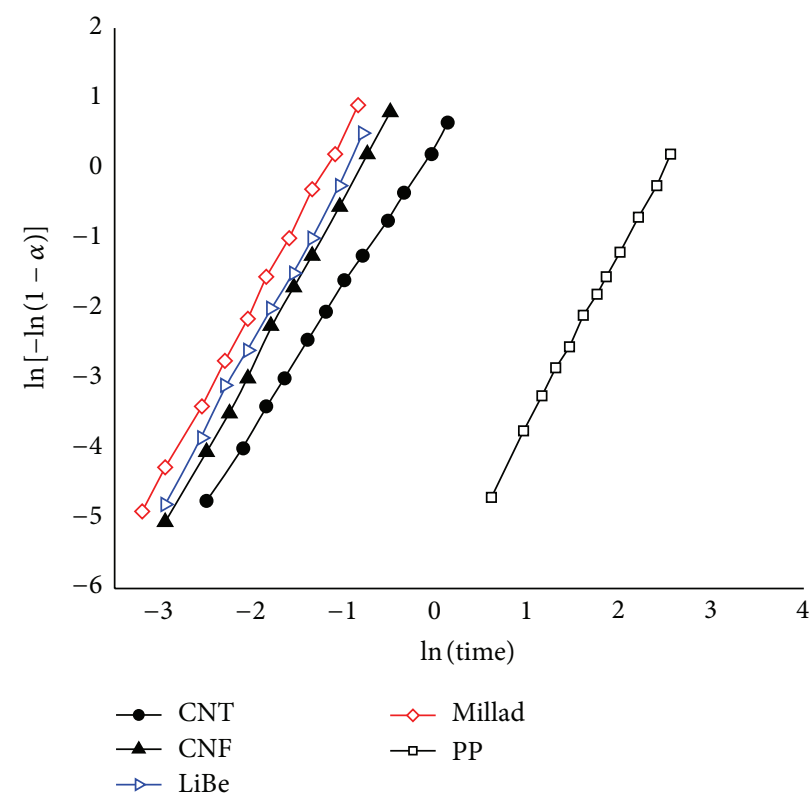

(b)

FIGURE 4: (a) Variation of the relative crystallinity versus time, of pure PP and PP with 0.1 wt\% nucleating agent. (b) Avrami plots of pure PP and $\mathrm{PP}$ with $0.1 \mathrm{wt} \%$ nucleating agent at $120^{\circ} \mathrm{C}$.

To study the isothermal crystallization, the following equation, derived from the Avrami model, was used:

$$
\begin{aligned}
\alpha & =1-\exp \left(-K t^{n}\right), \\
1-\alpha & =\exp \left(-K t^{n}\right), \\
\ln (1-\alpha) & =-K t^{n} \longrightarrow \\
-\ln (1-\alpha) & =K t^{n}, \\
\ln [-\ln (1-\alpha)] & =n \cdot \ln (K t), \\
\underline{\ln [-\ln (1-\alpha)]} & =n \cdot \underline{\ln (t)}+n \cdot \ln (K),
\end{aligned}
$$

where $\alpha$ is the weight fraction that has passed from the amorphous to the crystalline state, as a function of the time t. $K$ is the Avrami constant and $n$ is the Avrami exponent. $K$ and $n$ are used to interpret the nucleation mechanism and the overall crystallization rate of the polymer. $K$ and $n$ are obtained from a plot of $\ln [-\ln (1-\alpha)]$ versus $\ln (t)$. Figures 4(a) and 4(b) show the Avrami plots for the PP compositions studied.

Values of $K, n$, and $t_{1 / 2}$ are presented in Table 4 . The fractional $n$ values are accounted for in the Avrami theory by assuming some overlapping of primary nucleation and growth [22]. $n$ values obtained are between 2.0 and 3.0 for all the PP compositions studied.

The effect of the nucleating agents is clearly seen in the development of the crystallization rate (Table 4). The crystallization rate-measured by the half-life time of crystallization, which was determined experimentally-for the given temperature of $120^{\circ} \mathrm{C}$, indicates an increase in the velocity of crystallization induced by the nucleating agent
TABle 4: Crystallization temperature $T_{c}$, Avrami's constant $K$, Avrami's exponent $n$, and crystallization half-life time $t_{1 / 2}$ for $\mathrm{PP}$ at different temperatures. In all cases, the nucleating agent concentration was $0.1 \mathrm{wt} \%$.

\begin{tabular}{lcccc}
\hline Sample & $T_{c}\left[{ }^{\circ} \mathrm{C}\right]$ & $n$ & $K$ & $t_{1 / 2}[\mathrm{~min}]$ \\
\hline \multirow{3}{*}{ PP } & 115.0 & 2.58 & 0.17 & 1.7 \\
& 117.0 & 2.71 & 0.052 & 3.2 \\
& $\mathbf{1 2 0 . 0}$ & $\mathbf{2 . 6 1}$ & $\mathbf{0 . 0 0 2}$ & $\mathbf{8 . 2}$ \\
& 122.0 & 2.49 & 0.0018 & 10.5 \\
\hline PP-CNT & 115.0 & 2.84 & 74.11 & 0.17 \\
& $\mathbf{1 2 0 . 0}$ & $\mathbf{2 . 7 4}$ & $\mathbf{3 7 . 1 9}$ & $\mathbf{0 . 3 2}$ \\
& 125.0 & 2.48 & 6.002 & 0.59 \\
& 127.0 & 2.58 & 0.606 & 0.82 \\
\hline \multirow{4}{*}{ PP-CNF } & 115.0 & 3.10 & 134.32 & 0.18 \\
& $\mathbf{1 2 0 . 0}$ & $\mathbf{2 . 9 8}$ & $\mathbf{4 8 . 0}$ & $\mathbf{0 . 4 1}$ \\
& 125.0 & 2.52 & 3.7 & 0.87 \\
PP-LiBe & 127.0 & 2.65 & 1.79 & 1.39 \\
\hline \multirow{4}{*}{ PP-Millad } & $\mathbf{1 2 0 . 0}$ & $\mathbf{2 . 7 6}$ & $\mathbf{1 3 . 8 2}$ & $\mathbf{0 . 5 2}$ \\
& 122.0 & 2.67 & 4.74 & 0.81 \\
& 125.0 & 2.74 & 0.67 & 1.49 \\
& 127.0 & 2.58 & 0.08 & 2.34 \\
\hline \multirow{4}{*}{} & 118.0 & 3.47 & 19.45 & 0.40 \\
& 125.0 & $\mathbf{2 . 5 0}$ & $\mathbf{9 . 1 4}$ & $\mathbf{0 . 5 2}$ \\
& 127.0 & 1.93 & 1.15 & 2.52 \\
& & 2.05 & 0.05 & 4.80 \\
\hline
\end{tabular}

(Table 4). With CNT and CNF, it increases by a factor of $20-$ 25, compared to the pure PP and, with either LiBe or Millad, it increases by a factor of 15 . 

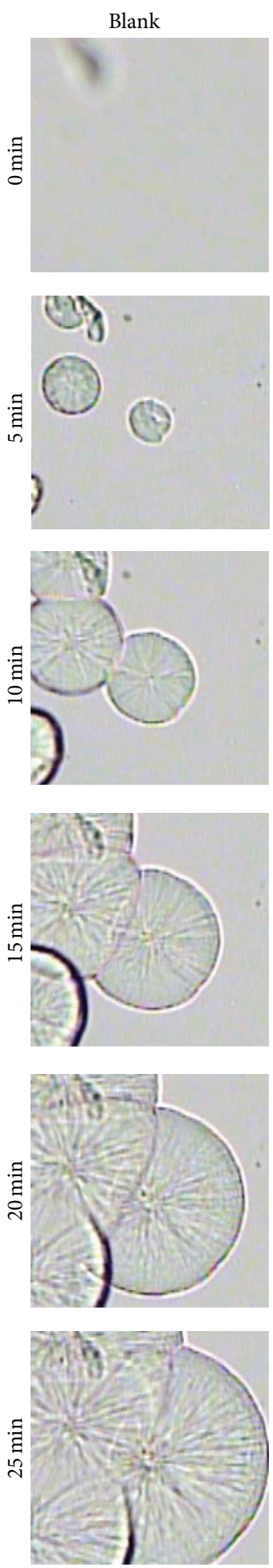

Millad
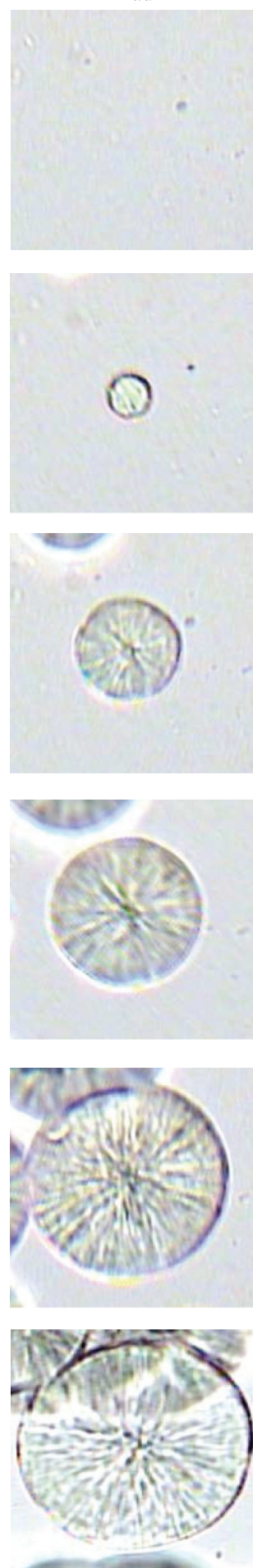

$\mathrm{LiBe}$
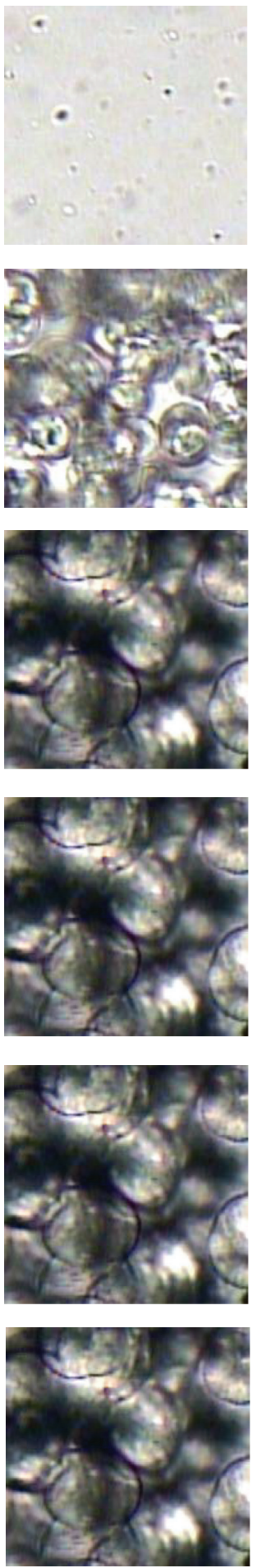

CNT
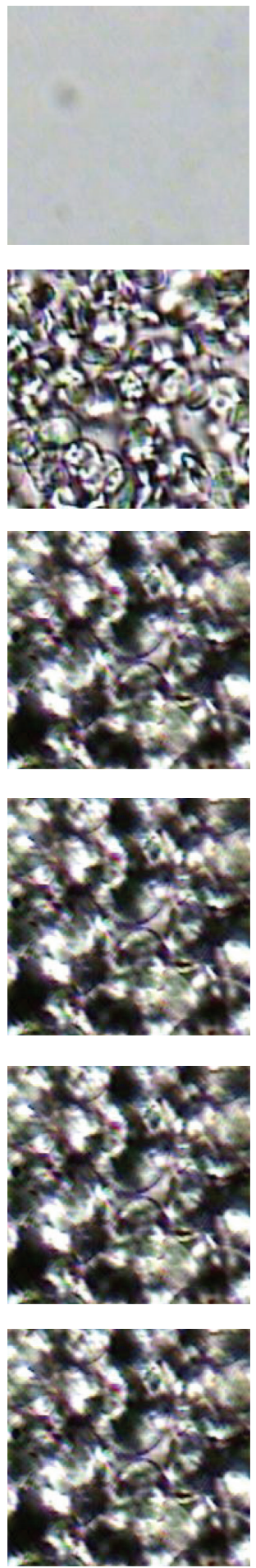

CNF
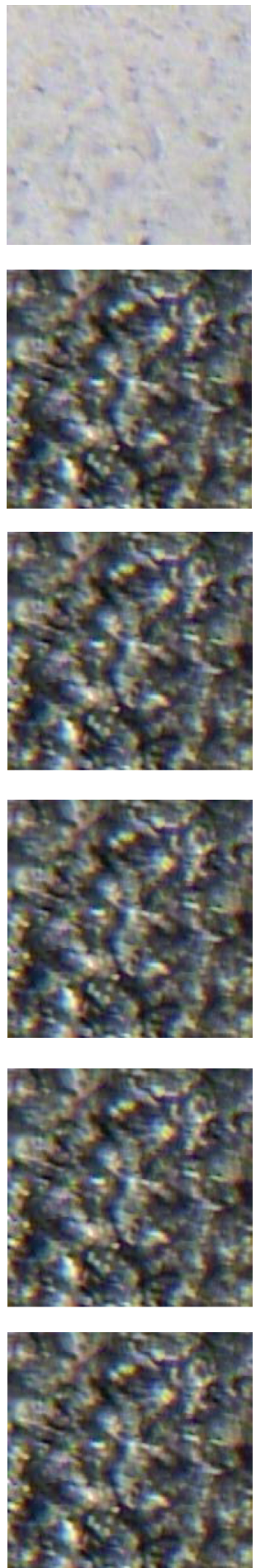

FIGURE 5: Crystallization process and crystal size of pure iPP and nucleated iPP composites at $135^{\circ} \mathrm{C}$, with 0.01 wt $\%$ of nucleating agent.

The spherulitic growth rate and number of nuclei are reflected in the Avrami constant $K$. In this case, the higher $K$ values indicate a higher number of nuclei for the PP compositions with carbon nanoparticles [2].
3.4. Spherulite Growth of iPP in Composites during Isothermal Crystallization. After assessing the different nucleating agents by their influence on the crystallization temperature, nucleating efficiency, and crystallization half-life time, their 
effect on the crystal size and crystallization rate of iPP is now examined. In this case, the nucleating agent concentration was $0.01 \mathrm{wt} \%$.

Results show that, in the case of the PP composites, the main difference in nucleating activity is as follows. (1) At $0.10 \mathrm{wt} \%$, the nucleating effect of Millad and $\mathrm{LiBe}$ is superior to that of both CNF and CNT. (2) But, at $0.01 \mathrm{wt} \%$, the nucleating effect of carbon nanoparticles is superior to that of Millad or LiBe.

The analysis of spherulitic growth under optical microscopy was carried out at $135^{\circ} \mathrm{C}$. This temperature was chosen simply because, at lower temperatures, the observed changes occurred very rapid.

Figure 5 shows the photographs of pure polypropylene and composites during isothermal crystallization at $135^{\circ} \mathrm{C}$.

It can be observed in Figure 5 that, after $5 \mathrm{~min}$, the crystal concentration in the carbon nanoparticles composites appears higher than for the LiBe composite. For the Millad composite, on the other hand, there is no nucleating effect at all and the crystal size remains approximately the same as that of the pure polymer.

Looking at the photographs, it can be assumed that the crystallization process of the pure polymer is completed after $25 \mathrm{~min}$; and the same can be said of the Millad composite.

The crystallization process of the LiBe composite, on the other hand, is completed around 10-15 minutes. Thereafter, the two remaining photographs at 20 and 25 min look very similar.

On the contrary, the crystallization process for the carbon nanoparticles composites is practically over after only a couple of minutes. The process is so fast that five minutes appear too long to differentiate the process.

But considering the effects of the studied nucleating agents on the crystallization temperature, the nucleating efficiency, and the crystallization half-life time, it can clearly be assumed that, at this low concentration of $0.01 \mathrm{wt} \%$, the carbon nanoparticles are right at their saturation point, whereas LiBe and Millad are far below this point.

It has been reported [30] that PP/CNT nanocomposites, with CNT contents above those studied here $(0.25$ and $0.5 \mathrm{wt} \%$ ), have higher nucleation density (number of nuclei in the polymer mass that give rise to crystals) than the pure $\mathrm{PP}$ and that not every nanotube can act as a nucleating site during crystallization. The authors commented that it seems that a minimum size of nanotube stack is needed to provide nuclei for crystal formation. In our case, nanocomposites containing lower CNT and CNF contents ( $0.01 \mathrm{wt} \%$ ) showed similar nucleation densities. It appears then that, as shown in our crystallization temperature, nucleating efficiency, and crystallization half-life time results, the carbon nanoparticles reach their saturation point at very low concentration.

\section{Conclusions}

The effect of different nucleating agents (carbon nanotubes, carbon nanofibers, lithium benzoate, and a sorbitol derivative) on the crystallization of Ziegler-Natta iPP was studied.

It was found that the four different nucleating agents promote the alpha crystalline form.
At the lower concentrations studied (0.001-0.01 wt\%), the carbon nanoparticles produced the higher $T_{c}$, whereas, at the highest concentration $(0.1 \mathrm{wt} \%)$, lithium benzoate and the sorbitol derivative produced a markedly higher $T_{c}$.

With $0.1 \mathrm{wt} \%$ nucleating agent, at $120^{\circ} \mathrm{C}$, the crystallization half-life time of PP, when using LiBe or Millad, was 15 times faster than for pure PP, whereas, when using carbon nanoparticles, it was 20-25 times faster.

At $135^{\circ} \mathrm{C}$, with $0.01 \mathrm{wt} \%$ of nucleating agent, the crystallization process of the Millad composite, as well as the pure polymer, is completed after $25 \mathrm{~min}$. But the crystallization process of the LiBe composite is completed after only $15 \mathrm{~min}$, and that of the carbon nanoparticles composites is practically over after only a couple of minutes.

The carbon nanoparticles reach their saturation point at very low concentration, namely, $0.01-0.05 \mathrm{wt} \%$, whereas the LiBe and Millad did not even appear to have reached their saturation point at the highest concentration studied $(0.1 \mathrm{wt} \%)$.

\section{Competing Interests}

The authors declare that they have no competing interests.

\section{Acknowledgments}

Two of the authors (Esperanza Elizabeth Martínez-Segovia and Flora Itzel Beltrán-Ramírez) thank CONACYT for granting them scholarships to carry their Ph.D. studies. Also, the authors gratefully acknowledge the financial support of CONACYT through Projects nos. CB-222805 and LN232753. Finally, the authors wish to thank M. Sánchez Adame, Francisco Zendejo, Rodrigo Cedillo, Conc. González, Jesús Rodríguez, Luis E. Reyes, Alejandro Espinoza, E. HurtadoSuarez, and D. Alvarado for their technical and informatics support.

\section{References}

[1] J. H. Botkin, N. Dunski, and D. Maeder, Improving Molding Productivity and Enhancing MEchanical Properties of Polypropylene with Nucleating Agents, Ciba Speciality Chemicals, 2002.

[2] K. Mai, K. Wang, Z. Han, and H. Zeng, "Study on the thermal stability of heterogeneous nucleation effect of polypropylene nucleated by different nucleating agents," Journal of Applied Polymer Science, vol. 83, no. 8, pp. 1643-1650, 2002.

[3] A. Menyhárd, M. Gahleitner, J. Varga et al., "The influence of nucleus density on optical properties in nucleated isotactic polypropylene," European Polymer Journal, vol. 45, no. 11, pp. 3138-3148, 2009.

[4] S. Nagasawa, A. Fujimori, T. Masuko, and M. Iguchi, "Crystallisation of polypropylene containing nucleators," Polymer, vol. 46, no. 14, pp. 5241-5250, 2005.

[5] M. Schmidt, J. J. Wittmann, R. Kress et al., "Crystal structure of a highly efficient clarifying agent for isotactic polypropylene," Crystal Growth and Design, vol. 12, no. 5, pp. 2543-2551, 2012.

[6] D. Vanzin and J. Cooke, "A novel clarifying/nucleating agent system for polyolefins," in Proceedings of the Annual Technical 
Conference of the Society of Plastics Engineers (ANTEC '91), vol. 49, pp. 1934-1941, Montreal, Canada, May 1991.

[7] R. Krache, R. Benavente, J. M. López-Majada, J. M. Perena, M. L. Cerrada, and E. Pérez, "Competition between $\alpha, \beta$, and $\gamma$ polymorphs in a $\beta$-nucleated metallocenic isotactic polypropylene," Macromolecules, vol. 40, no. 19, pp. 6871-6878, 2007.

[8] C. Mathieu, A. Thierry, J. C. Wittmann, and B. Lotz, "Specificity and versatility of nucleating agents toward isotactic polypropylene crystal phases," Journal of Polymer Science Part B: Polymer Physics, vol. 40, no. 22, pp. 2504-2515, 2002.

[9] K. Song, Y. Zhang, J. Meng et al., "Structural polymer-based carbon nanotube composite fibers: understanding the processingstructure-performance relationship," Materials, vol. 6, no. 6, pp. 2543-2577, 2013.

[10] D. Xu and Z. Wang, "Role of multi-wall carbon nanotube network in composites to crystallization of isotactic polypropylene matrix," Polymer, vol. 49, no. 1, pp. 330-338, 2008.

[11] C. Min, X. Shen, Z. Shi, L. Chen, and Z. Xu, "The electrical properties and conducting mechanisms of carbon nanotube/polymer nanocomposites: a review," Polymer-Plastics Technology and Engineering, vol. 49, no. 12, pp. 1172-1181, 2010.

[12] S. P. Bao and S. C. Tjong, "Mechanical behaviors of polypropylene/carbon nanotube nanocomposites: the effects of loading rate and temperature," Materials Science and Engineering A, vol. 485, no. 1-2, pp. 508-516, 2008.

[13] C. Marco, G. Ellis, M. A. Gómez, and J. M. Arribas, "Comparative study of the nucleation activity of third-generation sorbitolbased nucleating agents for isotactic polypropylene," Journal of Applied Polymer Science, vol. 84, no. 13, pp. 2440-2450, 2002.

[14] Y. Mubarak, P. J. Martin, and E. Harkin-Jones, "Effect of nucleating agents and pigments on crystallisation, morphology, and mechanical properties of polypropylene," Plastics, Rubber and Composites Processing and Applications, vol. 29, no. 7, pp. 307-315, 2000.

[15] M.-K. Seo, J.-R. Lee, and S.-J. Park, “Crystallization kinetics and interfacial behaviors of polypropylene composites reinforced with multi-walled carbon nanotubes," Materials Science and Engineering: A, vol. 404, no. 1-2, pp. 79-84, 2005.

[16] N. S. Murthy and H. Minor, "General procedure for evaluating amorphous scattering and crystallinity from X-ray diffraction scans of semicrystalline polymers," Polymer, vol. 31, no. 6, pp. 996-1002, 1990.

[17] S. Reyes-de Vaaben, A. Aguilar, F. Avalos, and L. F. Ramos-de Valle, "Carbon nanoparticles as effective nucleating agents for polypropylene," Journal of Thermal Analysis and Calorimetry, vol. 93, no. 3, pp. 947-952, 2008.

[18] D. W. van der Meer, J. Varga, and G. J. Vancso, “The influence of chain defects on the crystallisation behaviour of isotactic polypropylene," eXPRESS Polymer Letters, vol. 9, no. 3, pp. 233254, 2015.

[19] C. De Rosa, F. Auriemma, A. Di Capua et al., "Structureproperty correlations in polypropylene from metallocene catalysts: stereodefective, regioregular isotactic polypropylene," Journal of the American Chemical Society, vol. 126, no. 51, pp. 17040-17049, 2004.

[20] H. N. Beck, "Heterogeneous nucleating agents for polypropylene crystallization," Journal of Applied Polymer Science, vol. 11, no. 5, pp. 673-685, 1967.

[21] W. Stocker, S. N. Magonov, H.-J. Cantow, J. C. Wittmann, and B. Lotz, "Contact faces of epitaxially crystallized $\alpha$ - and $\gamma$-phase isotactic polypropylene observed by atomic force microscopy," Macromolecules, vol. 26, no. 22, pp. 5915-5923, 1993.

[22] M. M. Stasova, "Structure of the tetragonal modification of ammonium nitrate," Kristallografya (Crystallography Reports), vol. 4, pp. 242-243, 1959.

[23] B. Fillon, A. Thierry, B. Lotz, and J. C. Wittmann, "Efficiency scale for polymer nucleating agents," Journal of Thermal Analysis, vol. 42, no. 4, pp. 721-731, 1994.

[24] J. Varga, I. Mudra, and G. W. Ehrenstein, "Crystallization and melting of $\beta$-nucleated isotactic polypropylene," Journal of Thermal Analysis and Calorimetry, vol. 56, no. 3, pp. 1047-1057, 1999.

[25] J. Kang, H. Peng, B. Wang et al., "Investigation on the selfnucleation behavior of controlled-rheology polypropylene," Journal of Macromolecular Science, Part B: Physics, vol. 54, no. 2, pp. 127-142, 2015.

[26] M. Naffakh, Z. Martín, N. Fanegas, C. Marco, M. A. Gómez, and I. Jiménez, "Influence of inorganic fullerene-like WS2 nanoparticles on the thermal behavior of isotactic polypropylene," Journal of Polymer Science, Part B: Polymer Physics, vol. 45, no. 16, pp. 2309-2321, 2007.

[27] A. Menyhárd and J. Varga, "The effect of compatibilizers on the crystallisation, melting and polymorphic composition of $\beta$-nucleated isotactic polypropylene and polyamide 6 blends," European Polymer Journal, vol. 42, no. 12, pp. 3257-3268, 2006.

[28] Y.-F. Zhang, "Comparison of nucleation effects of organic phosphorous and sorbitol derivative nucleating agents in isotactic polypropylene," Journal of Macromolecular Science, Part B: Physics, vol. 47, no. 6, pp. 1188-1196, 2008.

[29] Y. Jin, A. Hiltner, and E. Baer, "Effect of a sorbitol nucleating agent on fractionated crystallization of polypropylene droplets," Journal of Polymer Science, Part B: Polymer Physics, vol. 45, no. 14, pp. 1788-1797, 2007.

[30] M. Razavi-Nouri, M. Ghorbanzadeh-Ahangari, A. Fereidoon, and M. Jahanshahi, "Effect of carbon nanotubes content on crystallization kinetics and morphology of polypropylene," Polymer Testing, vol. 28, no. 1, pp. 46-52, 2009. 

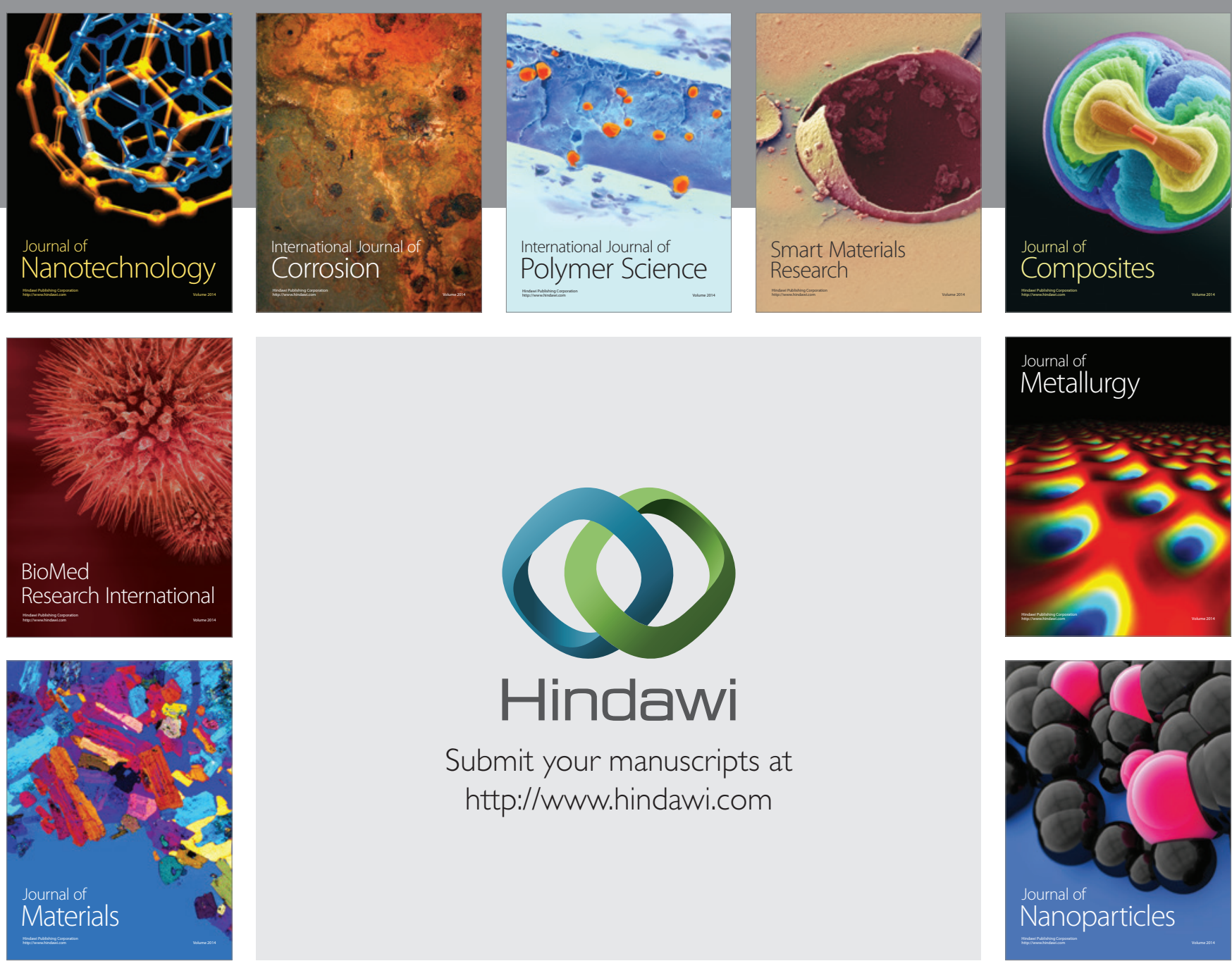

\section{Hindawi}

Submit your manuscripts at

http://www.hindawi.com

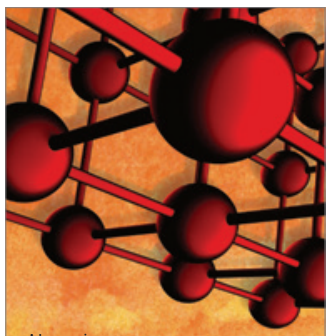

Materials Science and Engineering
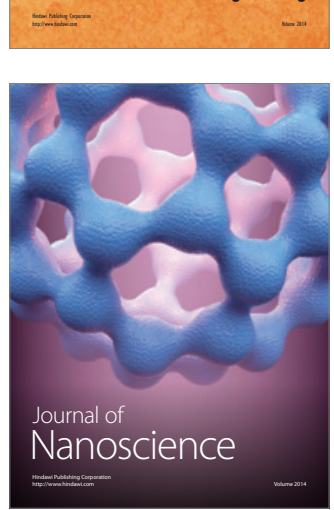
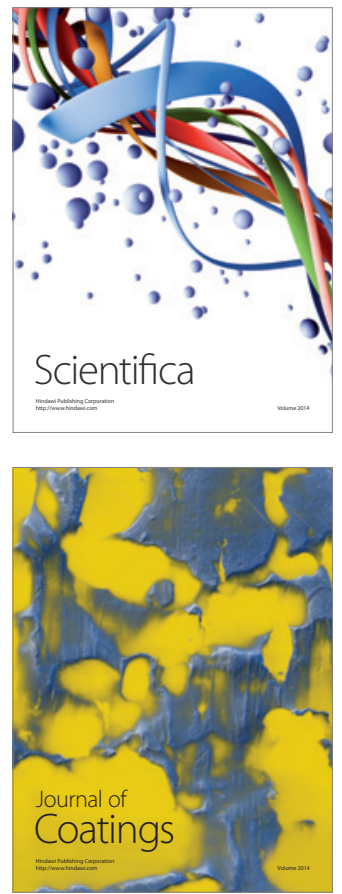
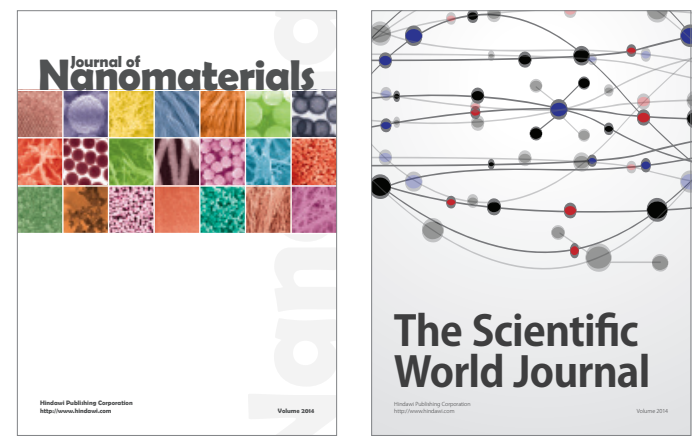

The Scientific World Journal
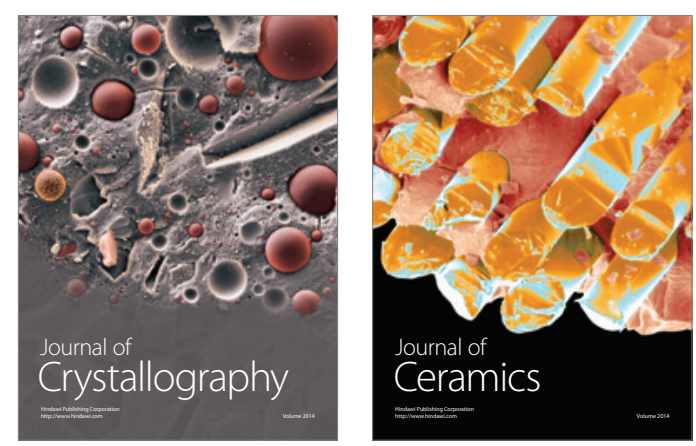
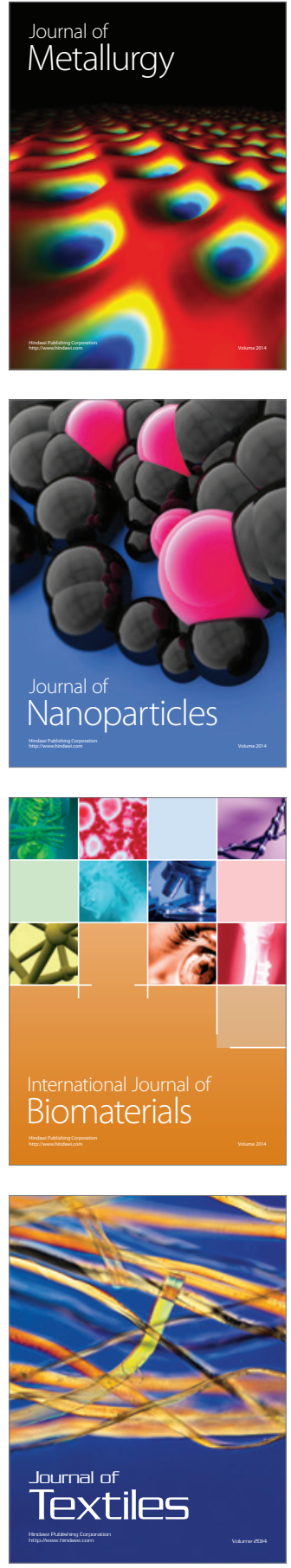